\title{
DIFERENTES ENFOQUES EN LA INVESTIGACIÓN DEL ARTE RUPESTRE DEL SISTEMA SERRANO DE VENTANIA
}

\author{
Fernando Oliva ${ }^{(1)}$, María Cecilia Panizza ${ }^{(2)}$, Mariana Algrain ${ }^{(3)}$
}

\author{
${ }^{(1)}$ CEAR - FHumyAr - UNR; FCNyM - UNLP; CRPAP - DPPC. Entre Ríos 758 (2000). Rosario, \\ Argentina. E-mail: fwoliva@unr.edu.ar; ${ }^{(2)}$ FCNyM (UNLP), CEAR (FHumyAr-UNR). Paseo del Bosque \\ s/n ${ }^{\circ}$ (1900). La Plata, Argentina. E-mail: mcpanizza@yahoo.com.ar; ${ }^{(3)}$ CEAR - FHumyAr - UNR; \\ CRPAP - DPPC. Entre Ríos 758 (2000). Rosario, Argentina. E-mail: algrainmariana@hotmail.com \\ Presentado el: 6/07/2010 - Aceptado 14/09/2010
}

\section{Resumen}

Desde fines de la década del '80 se inició el estudio sistemático del arte rupestre del Sistema Serrano de Ventania mediante diferentes estrategias teórica-metodológicas. En esta oportunidad se presenta una sintesis regional de las investigaciones en proceso. Entre los diversos enfoques de trabajo desarrollados, pueden mencionarse: a) la clasificación del universo de motivos presentes de acuerdo a criterios morfológicos; b) el registro, la clasificación y el monitoreo de los agentes de deterioro tanto de origen natural como antrópico, actuantes sobre y próximos a los motivos; c) el estudio de los aspectos rituales y simbólicos de las sociedades pampeanas, como puede ser el uso de enteógenos en un contexto shamánico, vinculados a la elaboración y significación del arte rupestre; y por último, d) los análisis de tipo semiótico, entendiendo a las representaciones rupestres como sistemas de signos estructurados, normados y comunicantes.

Palabras claves: Arte rupestre, sistema serrano de Ventania, cazadores recolectores.

\begin{abstract}
From the late 1980s, we work in the study of the pampas rock art through different methodological strategies. In this case we present a regional synthesis of the investigations relative to the rock art of the Ventania's Range. Among the diverse developed lines of work, can be mentioned: a) the classification of the motifs in styles, tendencies, and other categories, which makes possible its comparison with other graphical expressions of neighboring areas, and help us in the discussion of the spatial scales in the area and within the region; $b$ ) the documentation, classification and monitoring of the deterioration agents from natural or anthropic origin, operating on and next to the motifs; $c$ ) the ritual and symbolic aspects of the pampas societies, like the use of entheogens relative to the elaboration and meaning of the rock art in a shamanic context; and finally, d) the semiotic analyses, which understand the rock art like a system of structured, ruled and communicating signs.
\end{abstract}

Keywords: Rock art, Ventania's Range, hunters-gatherers. 


\section{Introducción}

La Región Pampeana presenta una geografía comprendida por amplias llanuras y por tres sistemas de serranías ubicados acotadamente, donde las sociedades indígenas pudieron efectuar sus representaciones en cuevas y aleros durante miles de años de ocupación. El arte rupestre pampeano ha sido abordado en los últimos años desde perspectivas teóricametodológicas diferentes, aunque con escasos estudios específicos relacionados con los sistemas de producción de las expresiones plásticas, por lo cual los aspectos vinculados con ideología, iconografía, simbología y cosmovisión han sido trabajados sólo parcialmente. En igual sentido, los procesos vinculados a la conservación, monitoreo y grado de deterioro de este particular tipo de registro arqueológico, tampoco han sido abordados hasta hace pocas décadas. En este trabajo se propone la utilización conjunta de diversos enfoques alternativos y complementarios para el estudio del arte rupestre del Sistema Serrano de Ventania, con el objetivo de generar una base de información más amplia y discutir sobre las posibles significaciones del arte rupestre, que aporten a la construcción de modelos explicativos para estas sociedades cazadoras recolectoras que habitaron el área mencionada.

El Sistema Serrano de Ventania representa una estructura en arco, cuyo rumbo general es Norte-Sureste, y posee una extensión máxima de $180 \mathrm{~km}$ en dirección NNO-SSE y de aproximadamente $130 \mathrm{~km}$ E-O (Schiller 1930). Cabe destacar que el mayor plegamiento se observa en el sector occidental, comprendiendo los cordones serranos de Puán, Curamalal, Bravard y Ventana, en tanto que el sector oriental presenta laderas más suaves y está constituido por las Sierras de las Tunas y de Pillahuincó (Suero 1972). Este plegamiento dio lugar a la formación de numerosas cuevas, las cuáles presentaron condiciones de habitabilidad con mayor estabilidad temporal, situación que ha quedado reflejada en las distintas evidencias de ocupaciones, especialmente aquellas que podrían haber actuado como soluciones óptimas a los problemas relacionados con la obtención de recursos críticos

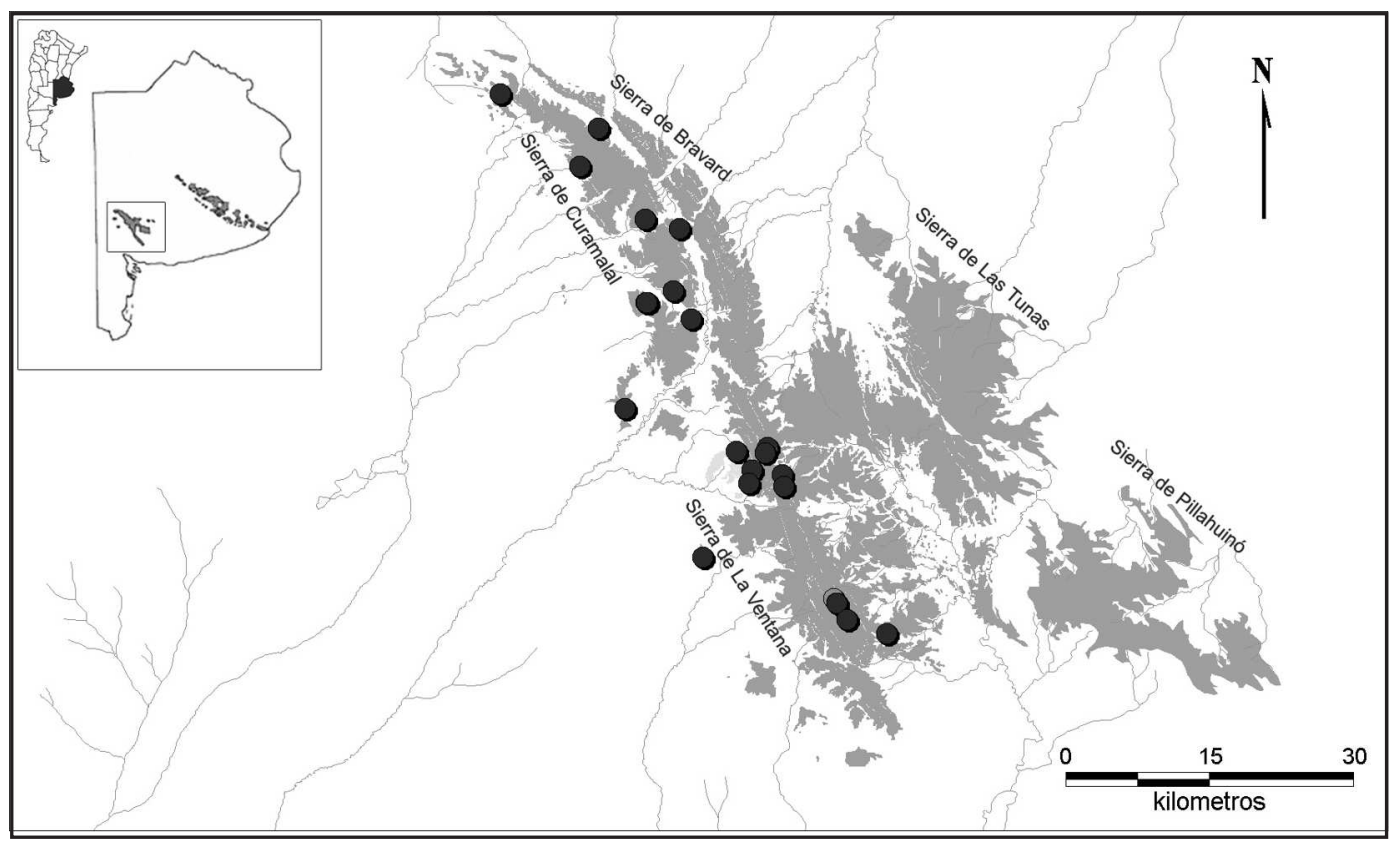

Figura 1. Mapa del área de estudio: Sistema Serrano de Ventania. 
(como materia prima lítica, cursos de agua, entre otros), dada su proximidad a los mismos (Oliva 2000). Hasta el presente, la mayoría de los sitios con arte rupestre se han registrado en el sector centro-occidental del sistema serrano (Figura 1).

Si bien el arte rupestre no ha sido considerado en forma sistemática a lo largo de la historia, es importante mencionar los antecedentes para su investigación en Sierra de la Ventana. Un primer trabajo es el de Eduardo Holmberg a fines del siglo XIX, quien dentro de un marco de estudios naturalistas, relevó las representaciones rupestres de la Gruta de los Espíritus (Holmberg 1884). Recién en la década del ‘70, Gradín $(1975,1978)$ reconoce sitios con arte rupestre de las Sierras de la Ventana. En la década del ‘ 80 , Scheines y colaboradores publican el hallazgo de la localidad arqueológica de Santa Marta (Pérez Amat et al. 1985). A fines de los '80, uno de los autores (F.O.) inicia junto con otros especialistas estudios sistemáticos en el área serrana de Ventania y su llanura adyacente, en donde se informa de varibilidad de registro arqueológico ie. sitios de campamento, de extracción de materias primas, sitios con arte rupestre entre otros lo cual posibilitó contar con un corpus de datos relevantes para el área de investigación (Oliva 1991, Madrid y Oliva 1994, Consens y Oliva 1999, Oliva 2000a; Oliva et al. 2002).

Existen varios centenares de cuevas y aleros dentro del Sistema Serrano de Ventania, de los cuales, hasta el momento sólo treinta sitios poseen representaciones rupestres. En todos los casos son pinturas, predominando el color rojo, el cual en muchas ocasiones se encuentra desvaído, y también se han hallado pinturas en tonalidades naranja y amarillo-ocre.

A partir del análisis de los motivos presentes en cada sitio, se detectó una tendencia hacia la representación de geométricos-abstractos, entre los cuáles destacan líneas paralelas, curvas, entrecruzadas, aisladas, en $\mathrm{V}$, en zigzag, guardas en $\mathrm{V}$, triángulos, tridígitos, alineamientos de puntos, reticulados, rombos, elipses, puntiformes, cruciformes, circunferencias, entre otros. Paralelamente a este repertorio, se observan representaciones figurativas en cuatro sitios (Oliva y Algrain 2004). La Gruta de los Espíritus es el sitio que presenta el mayor número de motivos de este tipo, consistentes en antropomorfos y mascariformes. En la cueva Santa Marta 1 (Pérez Amat et. al. 1985) se destacan manos en positivo. Por su parte, en la Cueva Florencio está representada la figura de un barco y la de una mano (Oliva et al. 2002). Asimismo en la cueva Arroyo Concheleufú Chico 1 se registró un antropomorfo. Finalmente existen otros dos sitios donde aparecen imágenes asignadas a posibles figurativos, los cuáles son La Montaña 3 y La Sofía 1.

Actualmente, se desarrollan diversas líneas de investigación sobre el arte rupestre del Sistema Serrano de Ventania, entre las cuales se destacan:

1. el registro y monitoreo de los agentes de deterioro naturales y antrópicos en los sitios arqueológicos en cuevas y abrigos rocosos; incluyendo tareas de digitalización y limpieza virtual de los motivos

2. la clasificación de los motivos en diversas categorías de agrupamiento

3. la vinculación del shamanismo con la elaboración de los motivos presentes en el arte rupestre

4. el análisis semiótico de las representaciones rupestres. 


\section{Registro y monitoreo de los agentes de deterioro naturales y culturales de los sitios con representaciones rupestres del Sistema Serrano de Ventania}

Desde el inicio de las investigaciones, se procuró registrar los agentes de deterioro que se encuentran afectando a los sitios con arte rupestre localizados en el Sistema Serrano de Ventania (Oliva 1992; 2000b), estas tareas han sido profundizadas mediante el abordaje de estudios multidisciplinarios (Gallego y Panizza 2005 a y b; Gallego y Oliva 2005; Guiamet $e$ t al. 2006). En general, se consideraron los procesos de transformación, a través de la realización de observaciones controladas en diferentes momentos del año, registros discriminados y toma de muestras de diferentes agentes de deterioro: geofísicos, geoquímicos, biológicos y antrópicos; incluyendo la realización de cultivos microbianos "in situ", correspondientes a diferentes sitios arqueológicos localizados en cuevas y aleros rocosos.

El factor más recurrentemente observado dentro de los agentes culturales ha sido la presencia de una importante cantidad de graffiti en casi todas las cuevas estudiadas (Oliva 1992, 2000b; Oliva y Sánchez ms.; Gallego y Oliva 2005). Relevar este factor en el área posibilitó documentar el aumento de la presencia de este tipo de deterioro en la mayor parte de las mismas. Además, se registraron otras acciones vandálicas, en forma de lascado de la roca extrayendo parte de las pinturas, pozos en cuevas con sedimentos y basura actual.

Entre los agentes geofísicos y geoquímicos reconocidos hasta el momento, la presencia de infiltraciones de agua, que conduce al agrietamiento y exfoliación de la roca, así como la acreción superficial de cristales, pueden ser observados en la mayoría de las cuevas, pero sin afectar directamente las pinturas. Asimismo, la humedad, a través de la exfoliación de la superficie rocosa, de la infiltración de humedad intersticial y capilar, y de la depositación de sales y otros componentes minerales, crea condiciones favorables para el establecimiento de microorganismos, que pueden llegar a afectar indirectamente a las pinturas (Gallego y Panizza 2005a). También pueden ser consecuencia de la humedad relativa de la superficie rocosa y de la acción de bacterias de nitrógeno, hierro, azufre o manganeso, la recurrencia de la presencia de carbonatación, óxidos de hierro y manganeso en el techo y paredes de las cuevas, afectando en pocos casos a las pinturas (Gallego y Panizza 2005b).

Con respecto a los agentes biológicos de deterioro observados en los sitios estudiados, pueden mencionarse a los arácnidos, coleópteros y otros artrópodos, destacándose la acción de los murciélagos y las aves a través de la nidificación y los excrementos, cuya acidez facilita la disolución del barniz y otras capas minerales protectoras naturales que posee la roca base (Gallego y Oliva 2005).

Finalmente, uno de los problemas más significativos que afecta las pinturas rupestres en Ventania, lo constituye el desarrollo de líquenes, ya que además de cubrir parcialmente a los motivos, genera un ambiente ideal para el crecimiento de musgos, helechos y gramíneas. También pueden modificar la composición química y mineralógica del basamento rocoso, ocasionando la corrosión del sustrato con la fracturación mecánica y la perturbación de minerales, creando partículas menores que las del material original, degradando el soporte y las representaciones rupestres (Guiamet et al. 2006). Particularmente, se realizó un seguimiento del desarrollo de los líquenes en el sitio Cueva Parque Tornquist 2 a partir del año 1999, evidenciado por un crecimiento exponencial en los líquenes próximos y sobre los motivos, como se advierte en las imágenes correspondientes a los años 2004 y 2008 (Figura 2). 
De esta manera, se observa que el deterioro de los sitios con arte rupestre del Sistema Serrano de Ventania se debe a múltiples agentes y causas vinculadas con factores multivariados. El resultado de estos procesos es una creciente obstrucción visual de las representaciones rupestres a través del tiempo, ya que proporciones significativas de las mismas han desaparecido y su visualización es difícil para registrarlas adecuadamente.

Este problema ha sido contrarrestado en alguna medida por el desarrollo de los programas de computación para el tratamiento de imágenes, y para el área de estudio esta línea de trabajo fue iniciada a partir del 2001 (Oliva y Sánchez m.s., Panizza 2006). Los pasos a seguir son pocos y relativamente sencillos, y varían en relación con las características del objeto que está siendo procesado. Estos procedimientos requieren la instalación de un programa de edición tal como Adobe Photoshop o Corel Photo Paint y del escaneo e importación de imágenes en la computadora. En esta tarea se utilizan dos principios del mejoramiento de fotografía digital: el establecimiento de una nueva escala de colores y la manipulación de la saturación de color para incrementar la visibilidad de las pinturas rupestres al ojo humano (David et al. 2001).
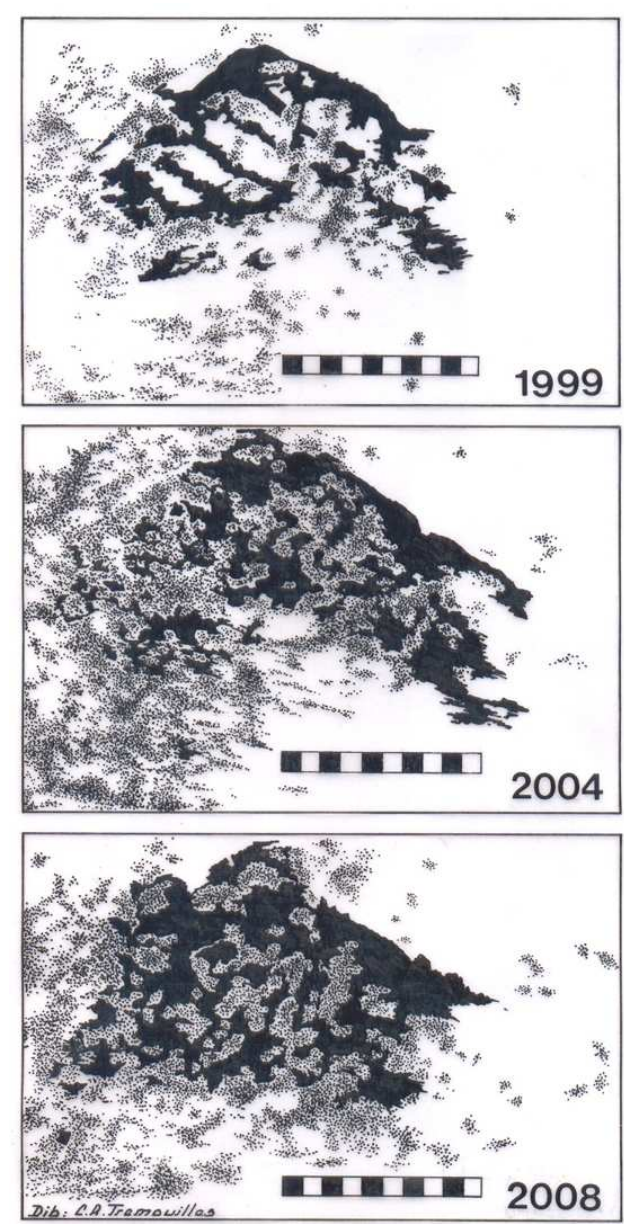

Figura 2. Cueva Parque Tornquist 2. Motivo cubierto con líquenes año 1999, año 2004 y año 2008.

En el último lustro, esta serie de pasos fue aplicada a varias representaciones rupestres del área de Ventania, entre ellas el motivo de la embarcación presente en Cueva Florencio (Panizza 2006), y a un motivo ubicado en el sitio Cueva Parque Tornquist, anteriormente interpretado como abstracto y en la actualidad considerado como un posible biomorfo (Oliva et al. 2007). Este último caso puede observarse en la Figura 3, donde el tratamiento digital de la imagen permitió distinguir elementos que se observaban muy desvaídos a simple vista.

Las imágenes digitales permiten aplicaciones importantes para la investigación, la conservación y el manejo de las representaciones rupestres. Hasta el momento se han digitalizado la totalidad de las imágenes disponibles (fotos y diapositivas) de las representaciones rupestres de los sitios del Sistema Serrano de Ventania, y se ha tratado un tercio de las mismas, obteniéndose buenos resultados mediante esta técnica. 




Figura 3. Tratamiento digital de imágenes, motivo correspondiente al sitio Cueva Parque Tornquist.

\section{Clasificación de las representaciones rupestres del Sistema Serrano de Ventania en diversas categorías de agrupamiento}

En la República Argentina los estudios de arte rupestre han estado influenciados durante largo tiempo por enfoques teóricos que se centraban en la descripción morfológica de los motivos, las asignaciones étnicas y las secuencias estilísticas. En este sentido, el corpus de arte presente en la Región Pampeana ha sido tradicionalmente analizado como parte de expresiones marginales, y como producto de influencias de regiones vecinas, especialmente del norte de Patagonia. Como ejemplos de estas interpretaciones, pueden citarse, entre otros, los trabajos de Menghín (1957) y Gradín (1980).

Para el desarrollo de esta línea de trabajo, se han considerado distintas propuestas operativas (Gradín 1988, Aschero 1988, Consens 1986), y se ha retomado la definición de estilo formulada por C. Aschero en cuanto "herramienta de análisis apta para reconocer lo particular, lo propio o lo idiosincrásico de los grupos humanos..." (1988:110). En base a esta supuesto metodológico y a presentaciones anteriores, (Madrid y Oliva 1994, Consens y Oliva 1999, Oliva 2000a) así como también al registro de nuevos sitios con arte en el Sistema de Ventania, se ha elaborado una clasificación de las representaciones rupestres (Oliva 2006, Oliva y Panizza 2007) considerando tanto los aspectos de producción del sistema rupestre en combinación con sus emplazamientos y su distribución, como las posibles vinculaciones de los elementos componentes de los motivos y su complejidad. Se han establecido hasta el momento cinco conjuntos de motivos, partiendo de aquellos más simples como las líneas paralelas, comprendiendo entre otros a líneas entrecruzadas, triángulos invertidos, polígonos irregulares, representaciones de manos, figuras antropomórficas, mascariformes, entre otros. Dada la variabilidad de motivos registrados en el área de Ventania, resulta operativa la clasificación propuesta por Carlos Gradin (1978), la que ha sido parcialmente presentada en diferentes oportunidades (ie. Madrid y Oliva 1994, Consens y Oliva 1999, Oliva 2000, Oliva y Algrain 2004, 2005, Oliva y Panizza 2007). De la información procesada cabe mencionar las siguientes consideraciones:

En este trabajo se analizaron 30 sitios con arte rupestre, los cuales se ubican en el sector central del Sistema de Ventania en las Sierras de Curamalal y Ventania (Abra Agua Blanca 1, Alero Corpus Christi, Arroyo Concheleufú Chico Cueva 1, Cerro Tres Picos Alero 1, Cerro Tres Picos Cueva 2, Cueva 1 Arroyo San Bernardo, Cuevas 1 y 2 Arroyo San Pablo, Cueva 2 del Valle Intraserrano, Cuevas 2, 3, 4 Parque Tornquist, Cueva Cerro Manitoba, Cueva del Toro, Cueva Florencio, Cueva Parque Tornquist, Gruta de los Espí ritus o Cueva 1 del Valle Intraserrano, Hogar Funke Cueva 3, La 


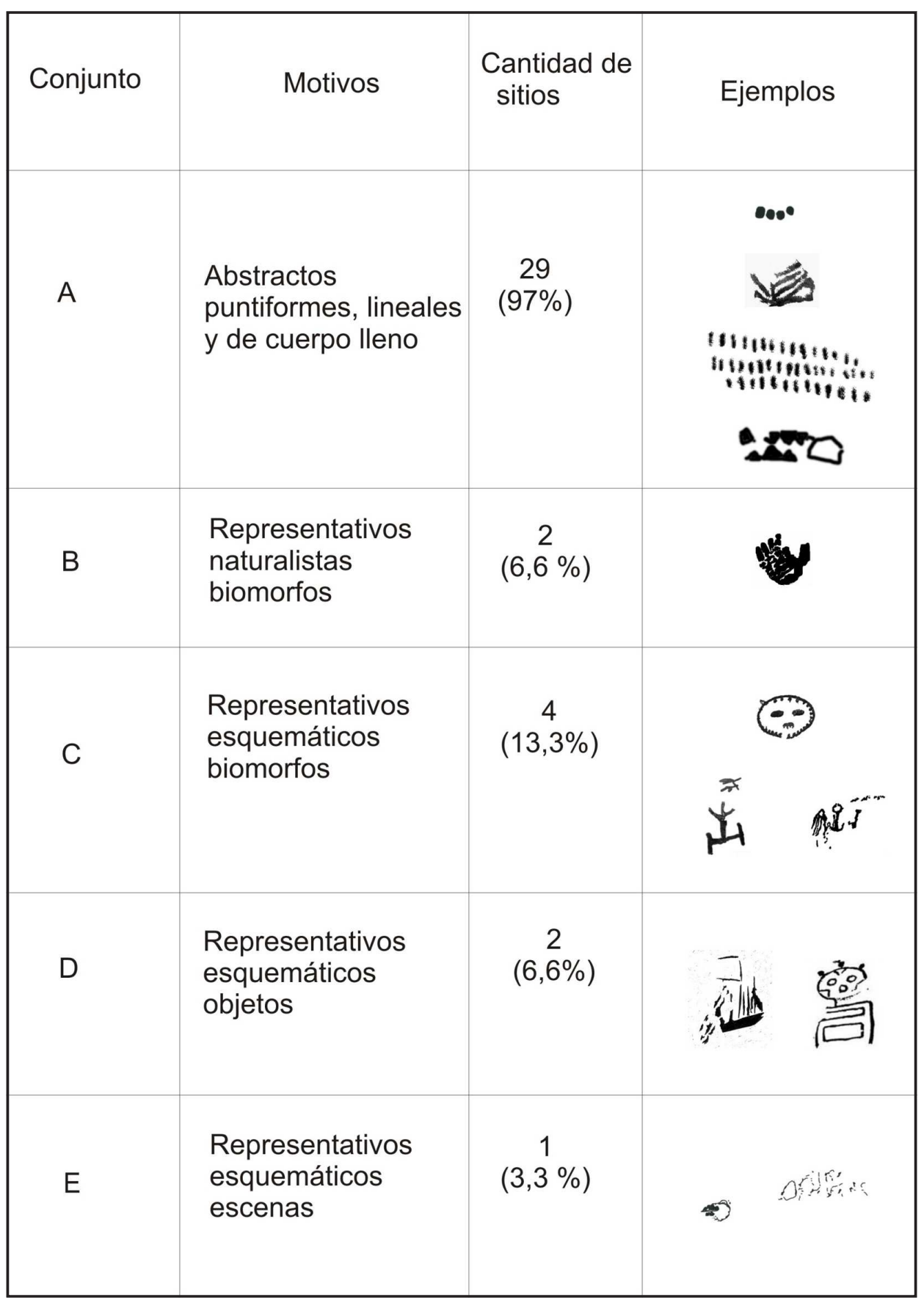

Cuadro 1. Grupos de tipos de motivos por sitio.

Montaña Sitio 3, La Sofia Cuevas 1, 2, 3, 4 y 6, La Sofia Cueva 7 o Cueva 3 del Valle Intraserrano, Santa Marta 1 a 5.

- Se determinaron cinco grandes grupos de tipos de motivos por sitio, en donde existe un predominio marcado de los motivos abstractos o no figurativos, representados en el $97 \%$ de los sitios estudiados (ver Cuadro 1). 
- Se definieron 43 tipos de motivos los cuales corresponden a 34 abstractos (79\%), constituidos por 3 abstractos puntiformes (6,97\%), 29 abstractos lineales $(67 \%)$ y 2 abstractos cuerpo lleno (4,65\%). Por su parte los figurativos comprenden 2 representativos naturalistas biomorfos $(4,65 \%), 4$ representativos esquemáticos biomorfos $(9,30 \%), 2$ representativos esquemáticos objetos $(4,65 \%)$ y 1 representativo esquemático escenas $(2,32 \%)$

- Finalmente cabe mencionar que predomina la ejecución de un solo tipo de motivo ya que en 21 cuevas u aleros $(70 \%)$ se presentan de esta manera. En 7 sitios $(23,33 \%)$ hay documentado 2 tipos de motivos. Solamente en 1 caso se encuentran 3 tipos de motivos y en otro 5 tipos de motivos con un $3,33 \%$ respectivamente.

\section{Vinculación del shamanismo con la elaboración de los motivos presentes en el arte rupestre.}

Una de las líneas de investigación que se está trabajando en el estudio del arte rupestre del Sistema Serrano de Ventania, se relaciona con buscar elementos que aporten a la comprensión de los aspectos rituales y simbólicos de las sociedades en el pasado. El arte rupestre, como modo de expresión y comunicación compuesto por símbolos visuales, posee variabilidad en su significado no solo a nivel cultural, sino individual, si bien existen formas de aproximación a su función simbólica a partir de un enfoque interdisciplinario. En este sentido, se trabaja con los aportes generados por la arqueología cognitiva y el llamado "modelo neuropsicológico", la etnobotánica, la etnografía, la antropología, entre otros campos.

La existencia de una recurrencia de motivos abstracto-geométricos en el arte rupestre de Ventania, podría estar señalando patrones culturales comunes entre los diversos grupos humanos que habitaron la región. Asimismo, motivos de esta índole aparecen representados a lo largo de todo el planeta, por lo cual, desde la arqueología cognitiva, se estudia la posibilidad de que estén relacionados con aspectos universales del Homo sapiens (Whitley 1998a, 1998b, Dowson 1998a, 1998b; Lewis Williams y Dowson 1988). Según estos trabajos, en los estados modificados de conciencia mediante el uso de sustancias psicoactivas o por mecanismos físicos del trance, se generan experiencias visuales y somáticas similares. Entre las visiones percibidas se destacan las imágenes llamadas fosfenos o visiones entópticas, tales como: grillas, líneas paralelas curvas y rectas, puntos, zig zags y filigranas.

Ya en la década del ‘30, Max Knoll (citado en Hamilton 2003) indujo mediante descargas eléctricas en sus pacientes la percepción de motivos luminosos denominados fosfenos, elaborando una "tabla" con aproximadamente 20 elementos (círculos concéntricos, espirales, estrellas, diamantes, líneas, curvas, puntos, entre otros). Posteriormente, en los años 70, Reichel-Dolmatoff estudió el uso de plantas alucinógenas entre los tukanos, destacando que las visiones producidas por las mismas eran representadas en la decoración de sus viviendas, de la cerámica, de cestas, atribuyendo lo que llamamos "arte" a las imágenes que ocurren en "el sueño de yajé" (Reichel-Dolmatoff 1972, citado por Furst 1992:111).

Particularmente en nuestro país, la relación entre arte rupestre y shamanismo ha sido abordada por diversos estudios arqueológicos (Schobinger 1997, Llamazares y Martínez Sarasola 2004, Casamiquela 1981, Madrid et. al 2000, Oliva y Algrain 2004, entre otros). Para el caso específico del Sistema Serrano de Ventania, si bien existe variabilidad en los motivos representados, el predominio de motivos abstractos y geométricos presentes en las manifestaciones artísticas podría estar relacionado tanto a la existencia de patrones culturales 
comunes, respondiendo a códigos compartidos por las sociedades que habitaron la Región Pampeana, como a cuestiones casi universales dependientes del universo neuropsicológico de la especie humana, como por ejemplo las visiones generadas en los estados modificados de la conciencia (Oliva y Algrain 2004, 2005, Algrain e.p.).

Considerando que las percepciones logradas durante los estados de trance son percibidas como verdaderas visiones de una realidad supranatural, muchas de las representaciones del arte shamánico, tanto abstractas como figurativas, podrían corresponder a seres o potencias del mundo mitológico (Algrain 2003). Asimismo, el arte shamánico junto a otros elementos simbólicos, en relación a su significación y uso en una escala macro regional, estarían posiblemente contribuyendo a los procesos de adaptación, control y significación del paisaje social (Oliva y Algrain 2005).

Estas interpretaciones intentan una perspectiva transcultural, dado que tanto el arte como el shamanismo tienen una dimensión universal más allá de sus manifestaciones culturales, particulares, históricas y relativas (Llamazares 2004). Un pilar importante para poder sostener esta interpretación es la disponibilidad en el área de estudio de recursos para la inducción del éxtasis, como es el caso de las plantas y hongos con propiedades psicoactivas. En este sentido cabe señalar que la Región Pampeana cuenta con potenciales enteógenos, como las siguientes especies de plantas y hongos: Datura feroz, Ipomea violácea, Nicotiana glauca, N. longiflora, N. noctiflora, Sida rhombifolia, Psathyrella candoleana y Psilocybes cubensis (Algrain 2003).

Con respecto a los relatos etnográficos y crónicas de viajeros (Falkner 1957, Guinnard 1947, Gancedo 1973), aparece la mención del uso de plantas -especies de tabaco nativas y otras "mantenidas en secreto" - y por las descripciones de sus efectos, provocaban estados que hoy se rotularían como de trance shamánico o de conciencia modificada o ampliada. Asimismo, se conoce el uso de chamico (Datura ferox) entre grupos mapuches, y la preparación de una bebida "inebriante" (sic) a partir del molle (Schinus molle) entre los tehuelches, según Casamiquela (2000).

Si bien los estados de conciencia modificada pueden lograrse sin el consumo de enteógenos, desde la etnografía se conoce que casi todos los grupos etnográficos, salvo excepciones como el caso de los selk-nam (de los cuales no se tiene registro), utilizan algún tipo de sustancia para lograr el acceso a estos estados diferentes de percepción. Por esta razón, se cree pertinente continuar y profundizar en los estudios de paleoetnobotánica, orientados a la búsqueda de alcaloides y otro tipo de sustancias enteogénicas.

Teniendo en cuenta esta información de tipo etnográfica, se consideró oportuna la aplicación del modelo neuropsicológico (Lewis-Williams y Dowson 1988) para establecer comparaciones con los sitios arqueológicos con pinturas del Sistema Serrano de Ventania. Existe una clara similitud formal entre los estadios 1, 2,3, y 4 propuestos por Lewis-Williams y Dowson (op.cit.) con un número significativo de representaciones rupestres presentes en el área de estudio. El $97 \%$ de los motivos presentes en los sitios estudiados resultan de carácter geométrico, y están compuestos por representaciones de líneas rectas, paralelas, triángulos enfrentados, almenados, puntos, escaleras, zig zags, rombos, entre otros (Consens y Oliva 1999, Oliva 2000). Son precisamente algunos de éstos los patrones observados en las primeras etapas o estadíos del trance (ver Lewis Williams y Dowson 1988), como la representación de enrejado presente en Cerro Tres Picos Cueva 2, las líneas paralelas 


\begin{tabular}{|c|c|c|c|}
\hline Estadio & \multicolumn{2}{|c|}{ Motivos Entópticos } & $\begin{array}{l}\text { arte } \\
\text { rupestre } \\
\text { Ventania }\end{array}$ \\
\hline 1 &  & & 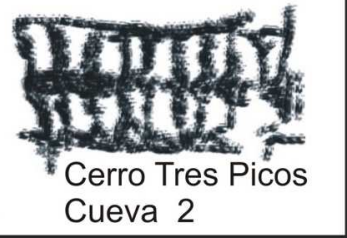 \\
\hline 2 & & & $\underset{\text { La Sofia } 7}{\text { Wum }}$ \\
\hline 2 & & $\begin{array}{l}1 \\
\vdots 1 \\
=1\end{array}$ & 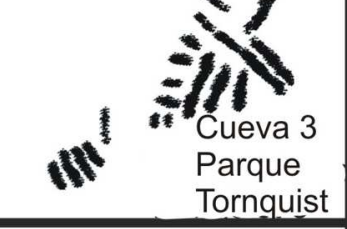 \\
\hline 4 & 15 & & $\begin{array}{l}\text { Cerro Tres } \\
\text { Cueva } 2 \\
\text { Cueva } 2\end{array}$ \\
\hline 5 & & & \\
\hline 2 & & & \\
\hline
\end{tabular}

Figura 4. Motivos entópticos y motivos rupestres presentes en los sitios del sistema serrano de Ventania.

registradas en 21 sitios estudiados, las líneas perpendiculares en diferentes ángulos, como la descripta en Cueva 3 Parque Tornquist, y las líneas en zigzag, documentadas en Cueva 2 Parque Tornquist y Cerro Tres Picos 2, entre otros sitios. 


\section{Análisis Semiótico de las Representaciones Rupestres}

Las representaciones rupestres poseen el carácter de sistema de representación o sistema de comunicación gráfica, lo cual permite proponer que las pinturas rupestres puedan ser estudiadas mediante los presupuestos y los instrumentos de una semiótica, ya que son un conjunto estructurado de signos que trasmiten información (Troncoso 2005).

Se considera que algunos elementos de la estructura de pensamiento de un grupo podrían encontrarse en los diversos "hechos sociales", entre los que se puede mencionar la producción de pinturas rupestres; y que a través de la semiótica se puede recuperar parte de la estructura cognitiva del grupo ejecutor. Este tipo de estudio es visto como un instrumento cognitivo para la comprensión del mundo, como metodología básica para el análisis o la producción del significado de los fenómenos. Este abordaje ha sido incorporado con el fin de centrar la investigación en el aspecto de comunicación implícita presente en las representaciones gráficas, tratando con sistemas de signos estructurados y comunicantes.

Para realizar este objetivo se aplica la metodología propuesta por Magariños (1996, 2003 y 2004), la cual se encuadra dentro de la semiótica general, que es aquella que desarrolla los conceptos de Peirce (1965) y de Saussure (1972), enfatizando la línea de investigación centrada en las imágenes visuales, conocida como semiótica visual (Magariños 1999). Su aplicación consiste principalmente en la identificación de las marcas presentes en las representaciones rupestres del área de estudio, y la determinación de sus formas de combinación, las cuales configuran los atractores. Se comenzó trabajando con los motivos que presentan un mayor índice de representatividad dentro del conjunto de las pinturas rupestres del Sistema de Ventania; las líneas paralelas, presentes en el $63 \%$ de los sitios estudiados. Este análisis contribuyó a definir cinco hipótesis de trabajo para este tipo de manifestación. La primera hipótesis propone que las líneas paralelas estarían en vinculación con alguna característica intrínseca del sitio, de su emplazamiento. La segunda hipótesis postula que las líneas paralelas en un sitio estarían comunicando información del ambiente extrasitio. La tercera hipótesis considera que las variaciones en los motivos se corresponderían a los marcadores territoriales de distintos grupos. La cuarta hipótesis destaca que la presencia de líneas paralelas sería un indicador de sacralización espacial de la cueva estudiada. Por último, la quinta hipótesis señala que la presencia de líneas paralelas estaría en vinculación con al menos dos de las hipótesis anteriores. En síntesis, estas hipótesis se pueden distinguir a grandes rasgos en aquellas que explican estas representaciones en relación con el ambiente, ya sea como marcador territorial o como indicador de algún recurso considerado crítico por las sociedades que las ejecutaron; y en aquellas interpretaciones que apuntan a un contenido intrínseco de dicha sociedad, en el caso de que fueran signos de identidad, pertenencia o propio de su cosmovisión.

\section{Consideraciones Finales}

En este trabajo se presentaron diferentes líneas de investigación que permitieron abordar el arte rupestre del Sistema Serrano de Ventania. Este tipo de registro podría responder a la existencia de un código que habría permitido la comunicación y significado un espacio en el cual adquirieron sentido las dinámicas socio-culturales. Se observa que la localización de los sitios con arte rupestre se relaciona con la presencia de cuevas y aleros dentro del Sistema Serrano, ubicándose próximamente a canteras de obtención de materia prima lítica (entre 
otros recursos presentes), y variando en torno a las diferentes condiciones de visibilidad (Oliva 2000).

Una de las primeras vías de aproximación ha sido la calibración de la acción transformadora de los agentes biológicos y culturales que intervienen en los diferentes sitios con arte rupestre del Sistema Serrano de Ventania. Con esta investigación se aportan a la construcción de una base de datos confiable y cuantificable, representando al mismo tiempo un testimonio de consulta para futuros abordajes del arte rupestre pampeano.

Estos estudios estuvieron orientados mediante la proposición de las siguientes hipótesis alternativas de trabajo:

Hipótesis 1: la evidencia de pinturas rupestres registrada actualmente en el Sistema Serrano de Ventania representaría sólo una parte disminuida de lo producido por las sociedades indígenas.

Hipótesis 2: la evidencia de pinturas rupestres registrada en la actualidad en el Sistema Serrano de Ventania no representaría una parte disminuida de lo producido por las sociedades indígenas.

Hipótesis 3: la evidencia de pinturas rupestres presente actualmente en el Sistema Serrano de Ventania no permitiría calibrar cuál fue el grado de pérdida del registro arqueológico.

La información de base obtenida a través de nuestras investigaciones en el área constituye un corpus inicial de datos que permitieron, al menos en forma parcial, poner a prueba nuestras hipótesis de trabajo. La localización geográfica del área de Ventania en un espacio rural, pero muy próximo a diferentes núcleos urbanos, favorece un mayor conocimiento de la ubicación de los sitios con arte rupestre. En relación a la destrucción por agentes antrópicos, si bien es de alto impacto, está siendo controlada mediante la implementación de políticas públicas. Dada su facilita detectar cuándo se realiza la acción vandálica y calibrar en poco tiempo la pérdida del patrimonio arqueológico.

En relación a los agentes biológicos, la información recabada al presente, tal es el caso de la Cueva Parque Tornquist 2, sugiere que esta pérdida del arte rupestre es altamente significativa y que puede llegar en determinada circunstancia (altitud, orientación, formación de grietas, insolación, entre otros) a ocasionar la pérdida en un porcentaje que oscila del 30 a $40 \%$ de las representaciones, lo cual apoyaría la primera de las hipótesis propuestas en desmedro de las otras hipótesis alternativas. En este sentido, se podría generar una nueva hipótesis en la formulación de nuevas líneas de investigación:

Hipótesis 4: la evidencia de pinturas rupestres presente actualmente en el Sistema Serrano de Ventania, si bien no permitiría calibrar cuál fue el grado absoluto de pérdida del registro arqueológico, posibilitaría reconocer el porcentaje relativo de pérdida de la información mediante el empleo de muestras más representativas y considerando las características diferenciales de los sitios.

Las nuevas tecnologías (aplicación de software) permiten por un lado, una actualización continua y el manejo de un universo mayor de información de la evidencia rupestre. Al mismo tiempo posibilita desarrollar diferentes aproximaciones que conllevan a la 
reinterpretación de la evidencia arqueológica, como es el caso del sitio Gruta de los Espíritus (Oliva y Sánchez ms., Oliva y Algrain 2005). Las aplicación de esta herramienta en conjunto con observaciones puntualmente dirigidas (accesibilidad de las cuevas, características topográficas, impacto del turismo entre otras) permitirán un mayor grado de calibración y de esta manera poner a prueba nuestra nueva hipótesis de trabajo.

En cuanto a la clasificación de los motivos, la propuesta presentada en este trabajo estuvo centrada en una clasificación descriptiva de acuerdo a la complejidad de la unidad constituyente. Sin embargo, es de destacar que esta clasificación no conlleva un criterio cronológico evolutivo, sino que el mismo estuvo centrado en un ordenamiento por tipo de motivo a fin de entender que la ejecución de cada uno de ellos estaría funcionando como una "herramienta de análisis apta para reconocer lo particular, lo propio o lo idiosincrásico de los grupos humanos..." (Aschero, 1988:110). La información arqueológica del área, ha permitido identificar ocupaciones en diferentes momentos del Holoceno (ie. Oliva et. al. 1991 a y b, Castro 1983). Entre la variabilidad de información registrada se han documentados sitios con diversas prácticas mortuorias (Barrientos et al. 2002), aprovisionamiento de materias primas (Oliva y Moirano 2001), entre otros temas. Asimismo, se han encontrado evidencias de sitios con ocupaciones pertenecientes al período de contacto hispano indígena (Oliva et al. 2000, Oliva y Lisboa 2009). Los resultados obtenidos reflejan que en los diferentes momentos, el área fue ocupada por sociedades que desarrollaban estrategias de subsistencia alternativas, fundamentalmente practicando la caza y la recolección en aquellos sitios del Holoceno medio y final e incorporando el manejo de ganado europeo durante el período conocido como hispano indígena.

Es extremadamente significativa la presencia de motivos abstractos con porcentajes superiores al 90 \% de las representaciones (Madrid y Oliva 1994, Consens y Oliva 1999, Oliva 2000, Oliva y Algrain 2005, Oliva y Panizza 2007). Este alto índice de representaciones de tipo abstractos geométricos rectilíneos, estaría vinculado posiblemente con generar códigos de información cuyos significados irían más allá del grupo ejecutor (Oliva 2002). Como se propuso anteriormente, existe una similitud entre algunos de estos motivos y las visiones experimentadas durante el trance, lo cual permite proponer un origen shamánico para los mismos. Incluso, los motivos figurativos podrían poseer una vinculación con el shamanismo, aunque más difícil de establecer (ver Oliva y Algrain 2004 y 2005). En este sentido, cabe aclarar que los motivos entópicos generados durante el trance, se consideran "potenciales referentes" para las representaciones rupestres (Algrain e.p.), lo cual haría necesaria una revisión de las clasificaciones de los mismos en figurativos y no figurativos (o abstractos $\mathrm{v}$ representativos según Gradín 1978), objetivo que trasciende el presente trabajo.

Un punto importante a considerar en el arte rupestre del Sistema Serrano de Ventania, es la presencia de motivos figurativos en un bajo porcentaje, algunos de ellos antropomorfos como está bien documentado en los sitios de Arroyo Concheleúfu Chico 1 y Gruta de los Espíritus, además de otro posible antropomorfo en la cueva La Sofia 1 (Holmberg 1884, Oliva 2000, Oliva y Algrain 2005, Oliva y Panizza 2007). Estas características del registro arqueológico se podrían explicar de acuerdo a dos hipótesis:

H1: la totalidad del repertorio presente en el Sistema Serrano de Ventania correspondería a diferentes expresiones de un código compartido por las sociedades indígenas que vivieron en el área y cuyo significado espacial habría perdurado en los diferentes momentos de ocupación de la región. 
H2: las diferencias observadas en el repertorio del arte rupestre de Ventania se corresponderían a códigos de comunicación desarrollados por las sociedades indígenas que habitaron el área investigada, cuyos significados habrían sido interpretados de manera diferencial en los sucesivos momentos de ocupación del territorio.

Estos dos propuestas, si bien antagónicas, están en directa vinculación en cuanto consideran al arte rupestre como un medio para la manipulación de las decisiones con respecto a la movilidad y al acceso a determinados recursos (Hartley y Wolley Vawser 2000), y al mismo tiempo como un medio de comunicación para el intercambio de información dentro y fuera del grupo que lo produce (Morwood 1998).

Asimismo, desde un marco de arqueología cognitiva, es posible formular la propuesta de que la recurrencia de motivos abstracto-geométricos en el arte rupestre de Ventania, podría estar señalando patrones culturales comunes, respondiendo a códigos compartidos, a la vez que posibilitaría su relación con cuestiones universales dependientes del universo neuropsicológico humano (Oliva y Algrain 2004, 2005).

En este sentido, las vías de estudio abordadas en nuestro trabajo, como aquellas vinculadas al análisis semiótico en el sentido de Magariños (1999), orientadas a explicar tanto la producción del significado de los fenómenos sociales como la generación de datos dentro de la dimensión interpretativa constituyen aproximaciones distintivas pero que pueden ser utilizadas de manera complementaria para formular modelos explicativos sobre el arte rupestre de la región con el fin de articularlos en una interpretación plausible y completa de los comportamientos de los grupos humanos que habitaron el Sistema Serrano de Ventania y su llanura adyacente en diferentes momentos del Holoceno.

\section{Agradecimientos:}

Al Comité Editorial de la Revista Comechingonia así como a los evaluadores que permitieron mejorar sustancialmente este trabajo. A los propietarios de los establecimientos donde se localizan los sitios con arte rupestre y a las instituciones que apoyaron esta investigación.

\section{Bibliografía citada}

Algrain, M.

2003. El arte rupestre del Sistema Serrano de Ventania. Aproximaciones desde un enfoque cognitivo. Tesis de Licenciatura inédita. Facultad de Humanidades y Artes, Universidad Nacional de Rosario.

e.p. Manifestaciones artísticas en la pampa argentina y su posible relación con los estados de trance shamánico. Anuario de Arqueología, Facultad de Humanidades y Artes, Universidad Nacional de Rosario.

Aschero, C.

1988. Pinturas rupestres, actividades y recursos naturales, un encuadre arqueológico. En Arqueología Contemporánea Argentina, H. Yacobaccio (Ed.). Pp: 109-145. Editorial Búsqueda.

Barrientos, G.; F. Oliva y M. Del Papa

2002. Historia predepositacional y tafonómica del entierro secundario del sitio Laguna Los Chilenos 1 (Provincia de Buenos Aires). Relaciones de la Sociedad Argentina de Antropología 27: 303-326. 
Casamiquela, R.

2000. Proyecto Etnobotánico de la Patagonia: Primer informe. http://ag.arizona.edu/OALS/ ICBG/publications/aspectos/casamiquela.html (14 de Diciembre de 1999).

1981. El Arte Rupestre de la Patagonia. Siringa Libros.

Castro, A.

1983. Noticia preliminar sobre un yacimiento en la Sierra de la Ventana, Sierras Australes de la Pcia. de Buenos Aires. Relaciones XV (N.S.): 91-107.

Consens, $\mathrm{M}$.

1986- San Luis - el arte rupestre de sus sierras. Tomo I y II. Fondo Editorial Sanluiseño. Dirección Provincial de Cultura. San Luis.

Consens, M. y F. Oliva

1999. Estado de las investigaciones en sitios con representaciones rupestres en la Región Pampeana, República Argentina. Actas del XI Congreso Nacional de Arqueología Argentina. Tomo III 119-127. La Plata.

David, B.; J. Brayer; I. F. McNiven y A. Watchman

2001. Why digital enhancement of rock paintings works: rescaling and saturating colours. Antiquity 75 (2001): 781-792.

Dowson, T. A.

1998a. Revelations of religious reality: the individual in San rock art.- World Archaeology 20:116-28.

1998b. Rain in Bushman belief, politics and history: the rock-art of rain-making in the southeastern mountains, southern Africa. En The Archaeology of Rock-Art. Editado por C. Chippindale y P.S. C. Tacon, pp. 73-89. Cambridge.

Falkner, T.

1957. Descripción de la Patagonia. Hachette S.A. Bs. As.

Furst, P.

1992. Alucinógenos y cultura. Fondo de Cultura Económica, México.

Gallego, M. y F. Oliva

2005. Evaluación de agentes de deterioro biológicos y culturales en los sitios en cuevas y abrigos rocosos del Sistema Serrano de Ventania, Provincia de Buenos Aires. Revista de la Escuela de Antropología. 11:131-146. Humanidades y Artes Ediciones. Escuela de Antropología, Facultad de Humanidades y Artes, Universidad Nacional de Rosario.

Gallego, M. y M. C. Panizza

2005a. Aproximaciones a los problemas de deterioro del arte rupestre. El sistema Serrano de Ventania (Provincia de Buenos Aires, Argentina), como caso de estudio. Trabajo presentado al $1^{\circ}$ Congreso Latinoamericano de Antropología. Rosario, Argentina:

2005b. Arte rupestre del Sistema Serrano de Ventania (Provincia de Buenos Aires). Estudio y monitoreo de los agentes naturales de deterioro. Libros de resúmenes del IV Congreso de Arqueología de la Región Pampeana Argentina: 159. Bahía Blanca, Provincia de Buenos Aires. 
Gancedo, O. A.

1973. Descripción de pipas de fumar tehuelches de la colección Francisco P. Moreno y Estanislao S. Zeballos. Revista del museo de La Plata. Tomo VIII: 47-71.

Gradin, C.

1975. Contribución a la arqueología de La Pampa (Arte Rupestre). Dirección Provincial de Cultura. Manzini Hnos. S.A.I.C. Santa Rosa. Provincia de La Pampa.

1978. Algunos aspectos del análisis de las manifestaciones rupestres. Revista del Museo Provincial 1: 120-133. Neuquén.

1980. Algunos aspectos de la metodología y el desarrollo del arte rupestre de PampaPatagonia. Actas de las Primeras Jornadas de Arte Rupestre de la Provincia de San Luis, Dirección Provincial de Cultura: 35-65. San Luis.

1988. Caracterización de las tendencias estilísticas del arte rupestre de la Patagonia (Provincias de Río Negro, Chubut y Santa Cruz, República Argentina). Contribuciones al Estudio del Arte Rupestre Sudamericano 2: 54-67.

Guiamet, P., S. Gomez de Saravia, M. V. Gallego y F. Oliva

2006. El arte rupestre del Sistema Serrano de Ventania (Provincia de Buenos Aires, Argentina). Las implicancias del biodeterioror en la preservación de sitios en abrigos rocosos. VII Simposio Internacional de Arte Rupestre. Arica.

Guinnard, A.

1947. Tres años de esclavitud entre los Patagones. Espasa-Calpe Argentina S.A.

Hamilton, R.

2003. Visiones de cerámica antigua. Imágenes que relatan una historia milenaria. Publicación electrónica: www.iadb.org/idbamerica/Archive/stories/1998/esp/c998k.htm (acceso 20 de Enero de 2003).

Hartley, R. y A. M. Wolley Vawser

2000. Spatial behaviour and learning in the prehistoric environment of the Colorado River drainage (south - eastern Utah), western North America. En The Archaeology of the Rock Art, Ch. Chippindale y P.S. C. Taçon (eds.) pp.185-211. Cambridge University Press.

Holmberg, E.

1884. La Sierra de Curá-malal (Currumalan). Informe presentado al exelentísimo señor gobernador de la provincia de Buenos Aires, Dr. Dardo Rocha. Buenos Aires.

Lewis-Williams, J. D. and T.A. Dowson

1988. The signs of all times: entoptic phenomena in Upper Palaeolithic art. Current Anthropology, 29 (2): 201-245.

Llamazares, A. M.

2004. Arte chamánico: visiones del universo. El lenguaje de los Dioses. Arte, chamanismo y cosmovisión indígena en Sudamérica. (Ana María Llamazares y Carlos Martínez Sarasola editores):: 67-125. Editorial Biblos. 
Llamazares, A. M. y C. Martínez Sarasola

2004. "Introducción". El lenguaje de los Dioses. Arte, chamanismo y cosmovisión indígena en Sudamérica. Ana María Llamazares y Carlos Martínez Sarasola editores: 13-20. Editorial Biblos.

Madrid, P. y F. Oliva

1994. Análisis preliminar de las Representaciones Rupestres Presentes en Cuatro Sitios del Sistema de Ventania, Provincia de Buenos Aires. Revista del Museo de La Plata: 199-223.

Madrid, P., G. Politis y D. Poiré

2000 Pinturas rupestres y estructuras de piedras en las Sierras de Curicó (extremo noroccidental de Tandilia, Región Pampeana). Intersecciones en Antropología (1):: 35-53.

Magariños de Morentín, J.

1996. Fundamentos Lógicos de la Semiótica y su Práctica. Ed. Edicial, Bs As.

1999. Operaciones semióticas en el análisis de historietas. En Fronteras de la semiótica. Homenaje a Desiderio Blanco, O. Quezada Macchiavello (Ed.), pp. 433-446. Universidad de Lima / Fondo de Cultura Económica. Perú.

2003. Hacia una semiótica indicial. Ediciós Do Castro. La Coruña.

2004. Los 4 signos. Diseño de las Operaciones Fundamentales en Metodología Semiótica. Razón y Palabra, $\mathrm{n}^{\circ}$ 38. http://www.razonypalabra.org.mx/anteriores/n38/jmagarinos.html.

Menghin, $\mathrm{O}$.

1957. Estilos del Arte Rupestre de Patagonia. Acta Praehistórica 1: 57-87. Buenos Aires.

Morwood, M. J.

1998. Sex, lies and symbolic behavior. Rock Art Research 15 (1):: 17-22.

Oliva, F.

1991. Representaciones rupestres del Sistema de Ventania, Provincia de Buenos Aires, República Argentina. Trabajo presentado al III Simposio Internacional de Arte Rupestre pp.3637. Santa Cruz de la Sierra, Bolivia.

1992. Dealing with modern graffiti in sites with rock art in Sierra de la Ventania, Argentina. Second AURA Congress, Symposium H, 30. Australian Rock Art Research Association: 26. Australia. 2000a. Análisis de las localizaciones de los sitios con representaciones rupestres en el Sistema Serrano de Ventania, Provincia de Buenos Aires. Arte en las Rocas. Arte Rupestre, menhires y piedras de colores en Argentina.(Ed. por M.M. Podestá y M de Hoyos):: 143-158. Buenos Aires. 2000b. Causas de Deterioro de sitios con representaciones rupestres en el sistema de Ventania. Provincia de Buenos Aires, República Argentina. Documentos del V Simposio Internacional de Arte Rupestre. Editor Matthias Strecker. pp. 35. Tarija, Bolivia.

2006. El arte rupestre del Sistema Serrano de Ventania de la Provincia de Buenos Aires, República Argentina: diferentes usos y propuestas. VII Simposio Internacional de Arte Rupestre. Arica.

Oliva, F. y M. Algrain

2004. Una aproximación cognitiva al estudio de las representaciones rupestres del Casuhati (Sistema Serrano de Ventania y llanura adyacente, Provincia de Buenos Aires). La Región 
Pampeana: su pasado arqueológico. C. Gradin y F. Oliva Editores: pp. 49-60. Editor Labor. Venado Tuerto. Santa Fe.

2005. Simbolismo en las sociedades indígenas en el sur del ecotono húmedo seco pampeano. ¿Arte shamánico? Revista de la Escuela de Antropología de Rosario X: 155-168.

Oliva, F., M. Algrain y C. Panizza

2002. Nuevos aportes a la interpretación del arte rupestre en el Sistema Serrano de Ventania. Tercer Congreso de Arqueología de la Región Pampeana Argentina. Universidad Nacional del Centro de la Provincia de Buenos Aires y Sociedad Argentina de Antropología: 15-16. Olavarría.

Oliva, F.; M. Algrain, L. Catella, J. Moirano, M. C. Panizza, G. Iparraguirre, M. Montal, L. Lisboa y L. Menendez.

2007. Arqueología de cazadores y recolectores de ambientes serranos. Sistema de Ventania y llanura adyacente, Provincia de Buenos Aires. II Jornadas de Extensión y Difusión del Parque Provincial Ernesto Tornquist.

Oliva, F., A. Gil y M. Roa

1991a. Recientes Investigaciones Arqueológicas en el Sitio San Martín 1 (BU/PU/5), Partido de Puán, Provincia de Buenos Aires. Shincal 3: 135-139. Publicación especial en Adhesión al X Congreso Nacional de Arqueología Argentina. Oliva, F., J. Moirano y M. Saghessi 1991b. Recientes investigaciones en el Sitio Laguna de Puán 1. Boletín del Centro 2: 127-138. Publicación del Centro de Registro del Patrimonio Arqueológico y Paleontológico de la Provincia de Buenos Aires. La Plata.

Oliva, F.; J. Moirano, E. Levin y D. Avila

2000. Investigaciones Arqueológicas de momentos Tardíos en el Abra de Saavedra, Provincia de Buenos Aires. En Libro de Resúmenes del II Congreso de Arqueología de la Región Pampeana Argentina. Pp. 18-19. Mar del Plata.

Oliva, F. y J. Moirano

2001. Estrategias para el estudio de la utilización de recursos líticos en el sur de la Región Pampena, República Argentina. En Arqueología Uruguaya hacia el fin del Milenio. Tomo 1: 521-537. Colonia del Sacramento Uruguay.

Oliva, F. y M. C. Panizza

2007. Estilos, agrupamientos y temas en el análisis de las representaciones rupestres. El Sistema Serrano de Ventania como caso de estudio. Resumen expandido publicado en Actas del XVI Congreso Nacional de Arqueología Argentina. Tomo II: 463-467. San Salvador de Jujuy.

Oliva F. y L. Lisboa

2009. Indicadores arqueológicos de cambio cultual en las comunidades indígenas pampeanas de los primeros momentos históricos (siglos XVI a XVIII). Región Pampeana, República Argentina. En BAR Internacional Series 1988, Juan García Targa y Patricia Fournier Garcia (eds.) Pp. 255267.

Oliva, F. y A. Sánchez

ms. Uso y valorización del patrimonio arqueológico rupestre en la Región Pampeana Argentina mediante el empleo de técnicas informáticas. 
Panizza, M. C.

2006 Digitalización y limpieza virtual de las representaciones rupestres del Sistema Serrano de Ventania (Provincia de Buenos Aires, Argentina). V Jornadas Arqueológicas Regionales. Programa Final y Resúmenes, pp. 30. Florentino Ameghino.

Peirce, C.S.

1965. Collected Papers. Cambridge. The Belknap Press of Harvard University Press.

Pérez Amat, M., D. Scheines y M. Bayón

1985. Noticia preliminar sobre hallazgos de pinturas rupestres en el establecimiento Santa Marta (Partido de Saavedra). Sapiens 5:86-90.

Saussure, F. de

1972. Cours de linguistique générale (1916). Éditions Payot. Paris.

Schiller, W.

1930. Investigaciones geológicas en las montañas del sudoeste de la Provincia de Buenos Aires. Anales del Museo de La Plata IV, primera parte (segunda serie): 11-96.

Schobinger, J.

1997. El arte rupestre del área andina como expresión de ritos y vivencias shamánicas o iniciáticas. Shamanismo Sudamericano. J. Schobinger (comp.), pp. 115. Editorial Almagesto. Buenos Aires.

Suero, T.

1972. Compilación geológica de las Sierras Australes de la Provincia de Buenos Aires. División Geología - L.E.M.I.T.M.O.P. Provincia de Buenos Aires.

Troncoso, A.

2005 Hacia Una Semiótica Del Arte Rupestre De La Cuenca Superior Del Río Aconcagua, Chile Central. Chungará, Revista de Antropología Chilena 37, 1: 21-35.

Whitley, D.S.

1998a. New approaches to old problems. Archaeology in Search of an Ever Elusive Past. En: E. Whitley (Ed) Reader in Archaeological Theory. Pp. 1-30. Routledge. London.

$1998 b$. Finding rain in the desert: landscape, gender and far western North American rockart. The Archaeology of Rock-Art. Editado por C. Chippindale y P.S. C. Tacon:11-29. Cambridge. 
